\title{
Treatment and Rehabilitation for Ruptured Flexor Digitorum Profundus Tendon after Steroid Injection in Trigger Finger and Carpal Tunnel Syndrome
}

\author{
Jinha Park (D), Si Young Roh (D) \\ Department of Plastic and Reconstructive Surgery, Gwangmyeong Sungae Hospital, Gwangmyeong, Korea
}

\begin{abstract}
The authors report cases of treatment and rehabilitation for flexor digitorum profundus (FDP) tendon rupture of the little finger in patients with history of steroid injection. In case 1, a 43-year-old man had been given two local corticosteroid injections on the palm over 8 weeks due to trigger finger of his left little finger. While doing chin-ups 1 week after the last injection, he experienced a painful snapping in his left little finger and lost flexion of the distal interphalangeal (DIP) joint. In case 2, a 49-year-old man had been diagnosed with ipsilateral carpal tunnel syndrome and was given local corticosteroid injection on the wrist. Two months after the injection the patient experienced sudden loss of flexion on the DIP joint of his left little finger while playing golf. During operation, an intratendinous rupture of the FDP tendon of the little finger was present and direct tendon repair was done in both patients. Continuous splint remolding was performed according to the range of motion. The range of motion was checked continuously at the ward and outpatient clinic every week. The final results of treatment were checked 6 months after surgery by the criteria developed by Strickland and Glogovac in 1980.
\end{abstract}

Keywords: Corticosteroid; Flexor; Tendon rupture; Rehabilitation

\section{서 론}

방아쇠수지와수근관 증후군은 수부외과 외래에서 볼수 있는 매우 흔한 질환들이다. 방아쇠 수지의 경우 $\mathrm{Al}$ 활차를 직접 절개하여 증상을 해소할 수 있다[1]. 그러나 많은 환자가 수술보다 는 비수술적 치료를 희망하고 있어 국소 스테로이드 주사를 통한 치료가 많이 쓰이고 있으며, 만족할 만한 결과가 보고되고 있다[2]. 또한 수근관 증후군 역시 횡수근 인대를 직접 절개하여 증상을 해소할 수 있으나, 일차적인 치료로 소염진통제 및 부목 고정과 함께 국소 스테로이드 주사를 임상에서 많이 활용하고 있다[3,4].

이러한 스테로이드 주사는 임상에서 일반적으로 많이 쓰이고 있으나, 건의 파열, 신경내 주 사로 인한 지속적인 통증, 수지 첨부의 허혈로 인한 괴사 등 드물지만 다양한 합병증이 보고되 고 있다[5]. 이러한 합병증 중 본원에서는 국소 스테로이드 주사를 시행 받은 방아쇠 수지와수 근관증후군 환자에서 동일하게 소지의 심지굴근의 파열이 확인되어 건 이식이나 건 이전 없이 직접 봉합을 통해 치료를 시행하였다. 이후 물리 치료와 함께 관절의 가동 범위에 따른 단계적 인 부목의 각도 조정을 통해 재활 치료를 시행하였다. 본 연구에 대해 환자들에게 연구 및 사진 사용에 대한 동의서를 취득하였으며 헬싱키 선언의 원칙에 따라 수행되었다.

\section{증 례}

각각 방아쇠 수지와 수근관 증후군으로 타병원에서 국소 스테로이드 주사를 시행 받은 후 소 지의 굴곡장애를 주소로 2017년 본원으로 두 명의 환자가 내원하였다(Table 1).
Case Report

Received: September 18, 2020

Revised: October 11, 2020

Accepted: October 11, 2020

\section{Corresponding author:}

Si Young Roh, M.D. Ph.D.

Department of Plastic and Reconstructive Surgery, Gwangmyeong Sungae Hospital, 36 Digital-ro, Gwangmyeong 14241, Korea Tel: +82-2-2680-7238

Fax: +82-2-2680-7755

E-mail: psczero@gmail.com

This is an Open Access article distributed under the terms of the Creative Commons Attribution Non-Commercial License (https://creativecommons.org/licenses/by-nc/4.0/) which permits unrestricted non-commercial use, distribution, and reproduction in any medium, provided the original work is properly cited.

(C) 2020 Korean Wound Management Society 
FDP rupture after steroid injection

Table 1. Flexor digitorum profundus tendon ruptures of the left hand little finger

\begin{tabular}{lclclccccc}
\hline Case & Age (yr)/sex & $\begin{array}{c}\text { Cause of steroid } \\
\text { injection }\end{array}$ & $\begin{array}{c}\text { Interval after last } \\
\text { injection }(w k)\end{array}$ & $\begin{array}{c}\text { Level of } \\
\text { rupture }\end{array}$ & Repair & $\begin{array}{c}\text { Follow-up } \\
(\text { mon) }\end{array}$ & $\begin{array}{c}\text { PIPJ ROM } \\
\left({ }^{\circ}\right)\end{array}$ & $\begin{array}{c}\text { DIPJ ROM } \\
\left({ }^{\circ}\right)\end{array}$ & $\begin{array}{c}\text { TAM } \\
\left({ }^{\circ}\right)^{\text {a) }}\end{array}$ \\
\hline 1 & $43 / \mathrm{M}$ & Trigger finger & 1 & Palm & Direct & 6 & $0-55$ & $0-55$ & Fair: 110 \\
2 & $49 / \mathrm{M}$ & CTS & 8 & Carpal tunnel & Direct & 6 & $0-85$ & $0-70$ & Excellent: 155 \\
\hline
\end{tabular}

PIPJ, proximal interphalangeal joint; DIPJ, distal interphalangeal joint; ROM, range of motion; TAM, total active motion; M, male; CTS, carpal tunnel syndrome.

a)TAM outcomes were evaluated according to Strickland and Glogovac 's criteria (see Table 2).
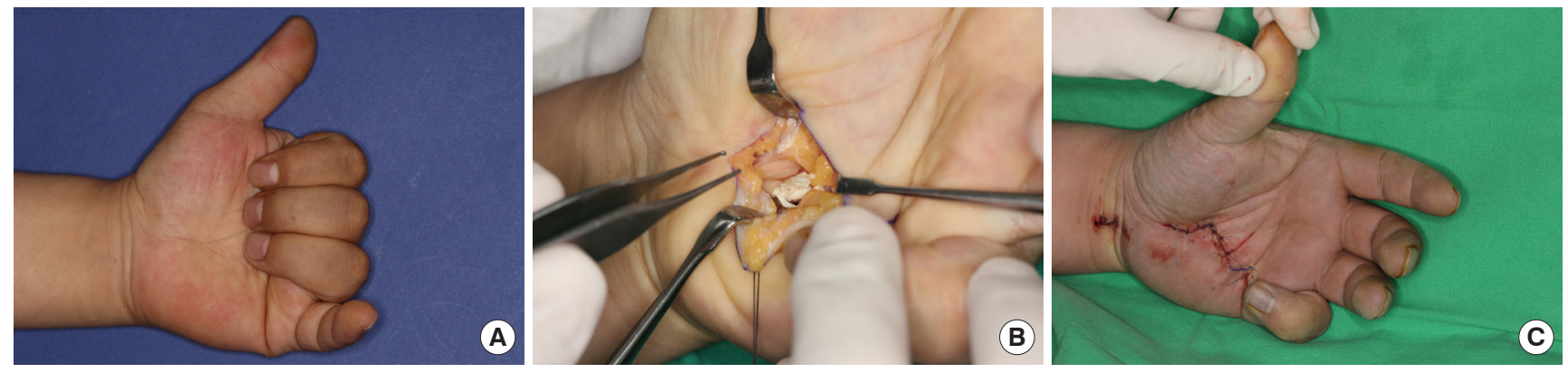

Fig. 1. Preoperative and intraoperative photos of case 2. (A) A 49-year-old patient presented flexion failure of the distal interphalangeal joint of his left little finger 8 weeks after receiving local steroid injection for carpal tunnel syndrome. (B) During surgery, completely ruptured flexor digitorum profundus tendon in the carpal tunnel was found. (C) Immediately after surgery, extension failure of the little finger was observed due to overcorrection.

\section{증례 1}

43세 남성 환자는 방아쇠 수지에 대해 8 주 간격으로 두 차례 좌측소 지에 국소 스테로이드 주사를 시행 받았다. 두 번째 주사를 시행 받은 1 주일 후 턱걸이를 하던 중 갑작스러운 딱 소리와 함께 소지에 통증 을 호소하였고, 이후 소지의 원위지 관절에 굴곡 장애가 발생하였다. 원위지 관절은 수동적으로는 $90^{\circ}$ 까지 굴곡이 가능하였으나, 능동적 인 관절의 움직임은 불가능하였다. 수술 소견상 원위부 수장부 손금 (distal palmar crease)까지 심지굴근이 근위부로 견인되어 완전히 파 열되어 있었다. 단열된 건의 양 끝을 건강한 굴곡건의 단면이 확인될 때까지 양측에서 변연절제한 후, PDS \#4-0를 이용하여 변형 Kessler 방식(modified Kessler method)으로 4겹 중심 봉합(4-stranded core suture)을 한 뒤 PDS \#4-0로 연속 봉합 방식(continous running method)으로 외건막 봉합(epitendinous suture)을 시행하였다.

\section{증례 2}

49세 남성 환자는 좌측의 수근관 증후군으로 수근관에 국소 스테로 이드 주사를 한 차례 시행 받았다. 8 주 후, 골프를 치던 도중 갑작스러 운 좌측소지 원위지 관절의 굴곡장애가 발생하였다. 좌측 소지의 원 위지 관절은 수동적 굴곡은 가능하였으나 능동적 굴곡은 불가능하 였다. 먼저 수근관 증후군의 교정을 위해 수직 수장부 주름(vertical palmar crease)에 $3 \mathrm{~cm}$ 세로 절개를 시행하여 정중 신경과 척골 신경 에 유의하여 수근관 인대 절개를 통해 개방적 감압술을 시행하였다. 이어 수근관에서 소지의 심지굴근이 완전 파열과 그 주위의 건막염 을 확인하였다. 단열된 건 주위의 건막염이 있는 부위를 변연절제한
후, 약 $0.5 \mathrm{~cm}$ 의 건의 결손이 발생하였다. 이후 양측 건을 PDS \#4-0를 이용하여 변형 Kessler 방식으로 4겹 중심 봉합을 한 뒤 PDS \#4-0로 연속 봉합 방식으로 외건막 봉합을 시행하였다. 변연절제 후 건의 결 손이 있었지만 중심 봉합 및 외건막 봉합만으로 직접 봉합을 시행하 였기에 근위지 관절과 원위지 관절의 신전 장애가 발생하였으나이는 추후운동을 통해 회복될 수 있다고 판단하였다(Fig. 1).

두 환자 모두 수술 후 첫 1 주간은 중수지관절을 $60^{\circ}$, 지관절을 $0^{\circ}$ 로 한 배부 보호부목(dorsal protection splint)을 유지하였다. 굴곡건의 유 착 방지를 위해 부목 안에서만 반대측 손을 이용하여 수동적으로 자 가 운동을 시행하였다. 봉합한 건의 재파열을 예방하기 위해 능동적 인 굴곡 운동은 시행하지 않았다. 수술 후 1 주 후, 능동적 자가운동 및 물리치료를 시작하였으나 부목은 지속적으로 유지하였다. 이후 통증 이 없는 상태로 원위지 관절의 운동 범위가 $30^{\circ}$ 이상 확인되었을 때, 기존 부목을 녹여 중수지관절을 $30^{\circ}$ 로 변경하였다(Fig. 2). 이때 붕대 는 근위지 관절까지만 감아서 원위지 관절의 운동에 제한이 없게끔 하였다. 능동적 자가 운동의 범위는 붕대에 수지가 걸리는 시점까지로 제한하였다. 이 시점까지 증례 1 환자는 수술 후 10 일이 소요되었으며, 증례 2 환자는 수술 후 7 일째부터인 능동적 자가 운동 및 물리치료를 시작한 시점부터 운동 범위가확인되어 바로 부목을 변경하였다.

두 환자 모두 수술 2 주째 퇴원하였으며, 이후 매일 외래로 내원하여 물리 치료를 받길 권고하였다. 이후 통증이 없는 상태로 원위지 관절 의 운동 범위가 $45^{\circ}$ 이상 확인되었을 때, 기존 부목을 녹여 중수지관 절을 $0^{\circ}$ 로 변경하여 전체적인 부목을 평평한 모양으로 변경하였고, 반대 손을 이용하여 원위지 관절과 근위지 관절이 모두 $90^{\circ}$ 가 되도록 

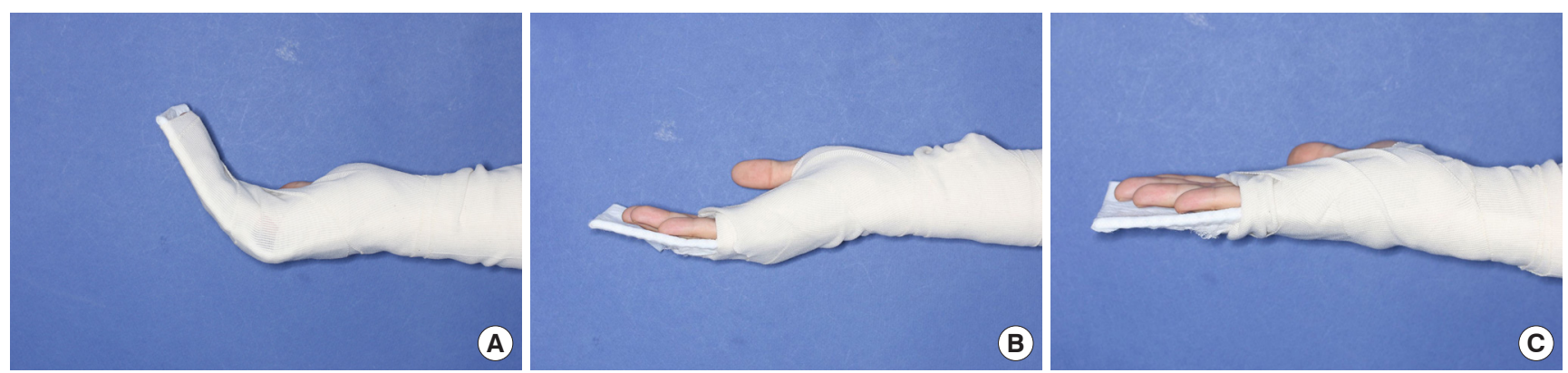

Fig. 2. Type of splint according to range of motion. (A) Immediately after surgery, a splint was molded for $0^{\circ}$ flexion at the IPJ and $60^{\circ}$ flexion at the MPJ. (B) The splint was changed to $30^{\circ}$ flexion at the MPJ, when range of motion of the DIPJ was more than $30^{\circ}$ without pain. Elastic bandage was only applied up to PIPJ of the little finger. (C) The splint was changed to be completely flat when range of motion of the DIPJ was more than $45^{\circ}$ without pain. IPJ, interphalangeal joint; MPJ, metatarsophalangeal joint; DIPJ, distal interphalangeal joint; PIPJ, proximal interphalangeal joint.

Table 2. Evaluation of outcomes according to Strickland and Glogovac's criteria

\begin{tabular}{lcc}
\hline Group & PIP + DIP return (\%) & PIP + DIP extension loss $\left(^{\circ}\right)$ \\
\hline Excellent & $86-100$ & $\geq 150$ \\
Good & $70-84$ & $125-149$ \\
Fair & $50-69$ & $90-124$ \\
Poor & $<50$ & $<90$ \\
\hline
\end{tabular}

PIP, proximal interphalangeal; DIP, distal interphalangeal.

수동적인 자가 운동을 교육하였다(Fig. 2). 이 시점까지 증례 1 환자는 수술 후 3 주가 소요되었으며, 증례 2 환자는 4주가 소요되었다. 이어 서 수술 6 주 후, 부목을 제거하였다. 수술 6 개월 후 증례 1 환자의 근 위지 관절과 원위지 관절 가동 범위는 모두 $55^{\circ}$ 로 확인되었고, 총 능 동 운동 범위(total active motion, TAM)는 $110^{\circ}$ 로 Strickland and Glogovac's criteria상 fair에 해당하였다. 증례 2 환자는 수술 6 개월 후 근위지 관절의 가동 범위는 $85^{\circ}$, 원위지관절의 가동범위는 $70^{\circ}$ 로 확 인되었다. 총 능동 운동 범위는 $155^{\circ}$ 로 Strickland and Glogovac's criteria상 excellent에 해당하였다(Table 2, Fig. 3).

\section{고 찰}

방아쇠 수지 및 수근관 증후군과 같은 건막의 염증에 대해 사용되는 국소 스테로이드 주사는 1953년 Howard 등[5]에 의해 소개된 이래 지 난 반 세기간 비수술적 치료의 대표적인 방법으로 임상적으로 널리 사용되고 있다. 그러나 이러한 국소 스테로이드 주사 후 발생한 건의 파열 또한 드물지만, 과거에 몇 차례 보고되었다. 방아쇠 수지에서 국 소 스테로이드 주사 후 일어난 건 파열은 Taras 등[6]과 Fitzgerald 등[7] 에 의해각각 무지와 중지의 굴근 파열로 보고된 바 있다. 또한 수근관 증후군에서 국소 스테로이드 주사 후 발생한 건의 파열 역시 Gottlieb 과 Riskin [8]에 의해 보고된 바 있다. 이외에 슬관절, 주관절, 견관절, 족관절 등 다양한 관절에서 국소 스테로이드 주사 후 건의 파열이 보 고되었다[9,10]. 이렇게 보고된 증례들에서 환자들은 수차례에 거쳐
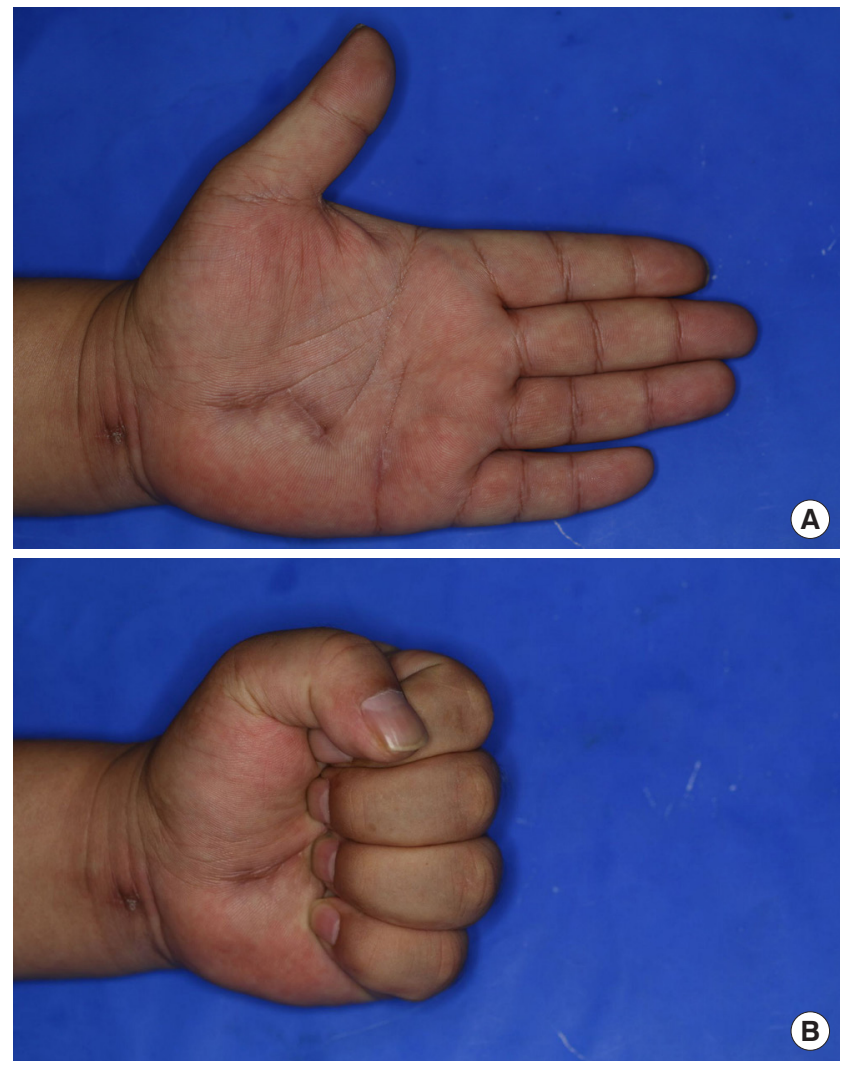

Fig. 3. Follow-up photos of case 2. (A, B) Six months after surgery, the range of motion of the proximal interphalangeal joint was $85^{\circ}$ and the range of motion of the distal interphalangeal joint was $70^{\circ}$. It was classified as excellent according to Strickland and Glogovac's criteria.

국소 스테로이드 주사를 시행 받았고, 짧게는 4 일, 길게는 4 년 후 건의 파열이 일어났다. 그러나 본원에서 보고하는 증례 2에서는 단한차례 의 주사를 시행 받고 8 주 후, 심지굴근의 파열이 확인되었다.

이러한 건의 자발적 파열에서는 직접 봉합, 일단계 또는 이단계에 거친 장장근을 이용한 건 이식, 천지굴근을 이용한 건 이전 등이 쓰일 
수 있다[11]. 이는 수술 중 굴곡건 및 주위 조직의 상태, 그리고 파열이 발생한 위치에 따라 결정된다. 위의 두 증례 모두 과거 국소 스테로이 드 주사로 인해 건막염 및 주위 조직의 염증이 있는 상태였다. 그러나 건막염 부위의 충분한 변연절제를 시행한 뒤 심한 건의 결손이 발생 하지 않는 한, 과교정이 일어나더라도 파열된 건의 직접 봉합이 가능 하다면 추가적인 다른 건의 희생 없이 한번의 수술만으로 환자는 일 상생활로 복귀가 가능하다. 본원에서 그동안 시행한 굴곡건의 봉합 에서는 $1 \mathrm{~cm}$ 미만의 굴건의 결손은 과교정을 시행한 뒤, 충분한 물리 치료를 통해 만족할 만한 결과를 보였으며, 결손이 있던 증례 2 의 환 자 또한, 물리치료를 통해 Strickland and Glogovac's criteria상 excellent에 해당하는 결과를 보였다.

굴곡건 봉합 이후에는 완전한 부목 고정을 통해 재파열을 막는 것 이 가장 중요하다고 그간 여겨져 왔다. 그러나 굴곡건 봉합 이후 부목 고정을 지나치게 오래 할 시 구축으로 인한 신전 장애가 발생하였고, 이에 주목하여 21 세기에는 다양한 굴곡건 봉합 이후의 재활 방법들 이 소개되고 있다. 이들의 공통적인 점은 오랜 부목 고정을 자제하고, 운동 치료를 통해 가동 범위를 확보하는 것이다[12]. 이러한 다양한 재활 치료 방법을 참고하여 본원에서도 굴곡건 봉합 이후 재활 치료 에 대한 프로토콜을 제작하였고, 이의 핵심은 통증이 없는 관절의 가 동 범위에 따른 부목의 각도 변경에 있다(Fig. 2). 기존의 재활 프로토 콜은 열상에 의한 굴곡건의 완전 파열에 대하여 작성되었으며, 상기 두 증례는 비록 열상이 아닌 스테로이드 주사에 의한 파열이었으나 동일한 프로토콜을 적용하여 재파열이 없이 만족스러운 결과를 얻 을수 있었다.

증례 1 의 환자보다 증례 2 환자는 수술 시 염증으로 인한 굴곡건의 결손이 있었고, 수술 직후 과교정으로 인해 수지가 굴곡된 상태였다. 이에 따라 예후가 더 불량할 것으로 예측되었으나, 재활 후 결과에서 는 더 나은 결과를 보였다. 그러나 증례 1 의 환자는 퇴원 후 2 주간 병 원에 내원하지 않은 상태로 물리치료를 받지 않았고, 이후 물리치료 의 빈도도 증례 2 환자보다 현저히 떨어졌다. 따라서 굴곡건의 파열 이후의 재활에 대한 순응도가 수술 전 상태보다 추후 예후에 더 큰 영향을 끼치는 것으로 생각된다.

본 두 건의 증례를 통해 임상적으로 국소 스테로이드 주사가 두 가 지 질환에서 많이 쓰이고 있고, 분명한 효과가 입증되었으나, 이가 일 으킬 수 있는 합병증을 반드시 생각해보아야 하며, 특히 한차례의 주 사만으로도 건의 파열이 일어날 수 있다는 것을 알리고자 한다. 또한 이러한 상황에서의 재활에서 통증이 없는 관절의 가동 범위에 따른 부목의 각도 조정을 통해 성공적인 재활을 시행할 수 있었기에 이를 보고하고자한다.

\section{이해 관계}

이 논문에는 이해 관계 충돌의 여지가 없음.

\section{ORCID iDs}

Jinha Park

Si Young Roh

https://orcid.org/0000-0003-3422-4662

https://orcid.org/0000-0002-8625-6124

\section{References}

1. Makkouk AH, Oetgen ME, Swigart CR, et al. Trigger finger: etiology, evaluation, and treatment. Curr Rev Musculoskelet Med 2008;1:92-6.

2. Schubert C, Hui-Chou HG, See AP, et al. Corticosteroid injection therapy for trigger finger or thumb: a retrospective review of 577 digits. Hand (N Y) 2013;8:439-44.

3. Shi $\mathrm{Q}, \mathrm{MacDermid}$ JC. Is surgical intervention more effective than non-surgical treatment for carpal tunnel syndrome? A systematic review. J Orthop Surg Res 2011;6:17.

4. Evers S, Bryan AJ, Sanders TL, et al. Corticosteroid injections for carpal tunnel syndrome: long-term follow-up in a population-based cohort. Plast Reconstr Surg 2017;140: 338-47.

5. Howard LD Jr, Pratt DR, Bunnell S. The use of compound $\mathrm{F}$ (hydrocortone) in operative and non-operative conditions of the hand. J Bone Joint Surg Am 1953;35-A:9941002.

6. Taras JS, Iiams GJ, Gibbons M, et al. Flexor pollicis longus rupture in a trigger thumb: a case report. J Hand Surg Am 1995;20:276-7.

7. Fitzgerald BT, Hofmeister EP, Fan RA, et al. Delayed flexor digitorum superficialis and profundus ruptures in a trigger finger after a steroid injection: a case report. J Hand Surg Am 2005;30:479-82.

8. Gottlieb NL, Riskin WG. Complications of local corticosteroid injections. JAMA 1980;243:1547-8.

9. Cowan MA, Alexander S. Simultaneous bilateral rupture of Achilles tendons due to triamcinolone. Br Med J 1961;1: 1658.

10. Ford LT, DeBender J. Tendon rupture after local steroid injection. South Med J 1979;72:827-30.

11. Pulvertaft RG. Tendon grafts for flexor tendon injuries in the fingers and thumb; a study of technique and results. J Bone Joint Surg Br 1956;38-B:175-94.

12. Neiduski RL, Powell RK. Flexor tendon rehabilitation in the 21st century: a systematic review. J Hand Ther 2019;32: 165-74. 